\title{
Pursuing security: economic resources and the ontological security of older New Zealanders
}

\author{
JULIANA MANSVELT*, MARY BREHENY† \\ and CHRISTINE STEPHENS:
}

\begin{abstract}
Access to economic resources influences the material conditions of life for older people, as well as the freedoms and capacities of older people to achieve the kind of lives they value. Security is one aspect of later life valued by older people. Ontological security provides a sense of order and continuity and needs to be understood in terms of the situated life experiences and circumstances of older people. The study reported in this paper analysed 145 qualitative interviews with New Zealanders aged $63-93$ in order to explore how participants understand ontological security. Varying levels of access to economic resources were associated with differing abilities of participants to manage the unpredictability of everyday life. Among the wealthy, security was strongly connected to the freedoms provided by ample financial resources. Contrary to what might be expected, those with the lowest levels of economic resources did not express higher levels of insecurity, but instead drew upon life experiences of managing and making do to construct a trajectory of security. Those with mid-range levels of economic resources expressed most insecurity, including anxiety over changing economic conditions and concerns over their ability to manage reductions in economic resources. In discussing the implications of this, the paper highlights the need to recognise ways in which access to economic resources intersect with life circumstances, past experiences and future social expectations to provide opportunities for all older people to pursue security as they strive to age well.
\end{abstract}

KEY WORDS-ageing, ontological security, economic resources, capability approach.

\section{Introduction}

Standards of living are understood to have significant effects on older people's ability to age positively, remain healthy and to participate in their

* School of People, Environment and Planning, Massey University, Palmerston North, New Zealand.

$\dagger$ School of Health and Social Services, Massey University, Palmerston North, New Zealand.

+ School of Psychology, Massey University, Palmerston North, New Zealand. 
communities (Townsend and Davidson 1982). For example, socio-economic inequalities of working life are often carried into early old age (Jatrana and Blakely 2008; Stephens et al. 2011 ) and may increase with age (Chandola et al. 2007). While variations in living standards are related to the health and wellbeing of older people, the economic resources available to people (comprising such things as access to goods and services, transport, savings, adequate housing and forms of insurance) may also influence the freedoms and choices available to people as they age and their ability to cope with change and risk. How economic resources impact on individuals' sense of security is unclear, and worthy of exploration given the considerable emphasis on 'positive ageing' in many Western democracies.

\section{Economic resources and the capability to achieve security}

A sense of risk and insecurity is an inescapable feature of the modern condition (McHugh 2007). Security as discussed in this paper comprises more than just physical safety, rather it is conceptualised as 'ontological security', a term coined by Laing (1965) in relation to the experiences of people with mental health issues, and extended by sociologist Anthony Giddens (1990, 1991). Giddens (1990) viewed security as the confidence that people have in the continuity of their self-identity and in the stability of surrounding social and material environments. An important part of ontological security is the trust or confidence people can have in the relationships that form part of their everyday existence. This trust also extends to the reliability of the networks and systems in which they are embedded to produce the outcomes they expect. Thus, ontological security may work across a number of domains to provide people with a source of physical, social and emotional wellbeing - a sense of control over the future, of feeling safe in place and time, and a means of coping with the unpredictability of everyday life.

While concern with risk might characterise the everyday lives of all people (Beck 1992), exposure and management of risk and uncertainty will vary across the lifecourse. Older people may face particular challenges to their 'world of normalcy'. Change in family circumstances and social networks, declining health or mobility, can all alter one's sense of security. Changing access to income and economic resources upon retirement is also likely to be significant (Ring 2005).

In a global world in which consumerism, commercialism and materialism are dominant, it is often argued that the possession of economic resources is a source of security and wellbeing (Underlid 2007). Much of the research related to ontological security has also emphasised the connectedness of 
the individual and society through material circumstances and economic resources. The concept has been applied selectively to experiences derived from living in and owning a home (Dupuis and Thorns 1996; Newton 2008; Padgett 2007), home heating and wellbeing (Gilbertson et al. 2006), housing tenure (Hiscock et al. 2001; Morris 2009), possessions (Noble 2004), security in public spaces (Cattell et al. 2008) and social security (Ring 2005). For example, the home has been identified as a key site and source of ontological security, with the 'home as haven' enabling dwellers to express autonomy and social status (Gilbertson et al. 2006: 953) and with material improvements (such as the heating of additional rooms) enhancing 'autonomy in the use of the home' (Hiscock et al. 2001: $5^{8}$ ). Sources of income and resources such as homes, food stocks, vehicles, savings and insurances may also contribute to ontological security.

Amartya Sen's (1999; Sen et al. 1987) capabilities approach suggests however, that the relationship between socially valued qualities of life (capabilities) and levels of economic resources is not straightforward. Sen (1999) argues it is not simply the possession of material and economic resources per se which matters, but the ways in which these resources provide capacities to act and function, creating and limiting freedoms, and producing the kinds of lifestyles and qualities that people value. However, those people with fewer economic resources are likely to have fewer options and freedoms available to them to achieve these socially valued capabilities (such as the freedom to be healthy, to live in security or to be educated) than those with more economic resources (King and Waldegrave 2009; Robeyns 2005; Sen 2000).

While the opportunities people have to pursue security can be expected to increase in relation to their ability to access and draw on economic resources, there are other factors which may intervene. The social, cultural, political and economic networks in which people are embedded, physical mobility, emotional, cognitive and spiritual wellbeing, education and forms of social capital may all influence people's capacities to achieve security. Consequently, material circumstances (such as access to suitable dwellings, income and food) combine with more intangible attributes (self-respect, confidence, wellbeing) to limit or enhance a person's functional capabilities (Morris 2009).

Political-economic contexts provide structures which impact on the economic resources available to older populations. Over recent decades, almost every industrialised country has made significant changes in their national pension system in response to the ageing of their populations (Schulz and Borowski 2006). Amongst such countries, New Zealand is unusual in providing a universal non-means-tested and non-taxed pension scheme, 'New Zealand Superannuation', which takes away some of the financial insecurity of ageing. Those over $6_{5}$ years receive an after-tax 
income providing older couples with approximately 66 per cent of the net average ordinary wage (33\% per partner in the relationship), and 40 per cent of the net average ordinary wage for older single people (Commission for Financial Literacy and Retirement Income 2012c). The level of New Zealand Superannuation payments is set by the government each year and adjusted to take into account rises in average wages and inflation. For single people and couples, superannuation pay-outs are generally higher than the unemployment or sickness benefit. For example, the unemployment or sickness benefit for a single person without children after tax is NZ $\$ 204.96$ at 1 April 2012, with the equivalent superannuation payment for a single person being NZ \$348.92 (excluding additional accommodation supplements and other benefits which are available for beneficiaries and Superannuants); (Ministry of Social Development 2012). Thus for those who have low incomes and/or have experienced income instability, reaching the age of eligibility for New Zealand Superannuation may offer greater economic security.

Approximately 93 per cent of those over 65 years old living in New Zealand receive superannuation payments, with ineligibility often a consequence of not meeting the residency criteria (Dixon and Hyslop 2008). Although 73 per cent of single people over 65 years and 86 per cent of older couples report receiving income from other sources such as private superannuation schemes, interest payments and returns on investments, for most people aged over $6_{5}$ years additional income is modest. Over 40 per cent of the population aged $6_{5}$ years or older is classified as having low income, defined as less than 6o per cent of the median gross equivalised household income (Carter and Imlach Gunasekara 2012). The majority of older New Zealanders are dependent on superannuation, with 40 per cent having no other income, and a further 20 per cent receiving 85 per cent of their income from New Zealand Superannuation, and around $5^{\mathrm{O}}$ per cent of people receiving less than NZ \$100 a week from nongovernment sources (Commission for Financial Literacy and Retirement Income $2012 a$ ).

New Zealand is one of two Organisation for Economic Co-operation and Development (OECD) countries (the other being Ireland) which does not have a mandatory individual saving scheme for retirement (Commission for Financial Literacy and Retirement Income 2012a). The introduction of the Government-subsidised 'Kiwi Saver' Scheme with contributions from employees and employers in 2007, has seen a significant increase in saving for retirement incomes, but only a small percentage of existing retirees are likely to benefit given its very recent introduction.

Annuitised incomes are also likely to reduce income insecurity for people as they age. However, while there are a number of private pension schemes 
available which provide annuitised income to overcome longevity risk in exchange for a lump sum or the de-accumulation of assets, take up and demand for annuitised income sources has been low (Commission for Financial Literacy and Retirement Income 2012b). Thus, although economic resources provide an important form of security in later life, economic resources and material conditions intersect with other aspects of individual and social lives to produce the experiences of ageing and coping in later life. Recognising these complex effects, we sought to examine the ways in which security was talked about and experienced in the lives of older New Zealanders across a range of living standards.

\section{Method}

This study examines the security provided by economic resources from the perspective and experience of older New Zealanders aged 63-93 years gained through 145 semi-structured interviews ( $5^{2}$ men, 85 women, eight couples). Participants were sampled purposively across a range of economic circumstances and locations across New Zealand. Participants represented a range of ethnicities including Pakeha (44.1\%), Maori (23.4\%), Pasifika $(7.5 \%)$, Chinese $(4.1 \%)$, non-New Zealand European $(13.8 \%)$ and Indian $(6.9 \%)$. Participants were recruited from large metropolitan cities, from smaller cities and towns, and from rural and remote areas. This sampling strategy was undertaken to ensure that interviews reflected a range of perspectives and life circumstances. For the purposes of this analysis, older people were grouped by similar economic resources. Across the demographic differences of age, ethnicity, and urban and rural living situations, older people with similar economic resources available to them talked about security in similar ways. Rather than considering the demographic differences, in this paper we explore the similar experiences of security that are made available by a level of economic resources.

Interviewers recruited participants from local networks in their own communities in order to establish rapport with participants and produce sensitive and informed conversations around the political, economic, environmental and social issues affecting their ageing in specific places and communities. All participants had been resident in New Zealand for at least five years. The New Zealand Deprivation Index (NZDep) was used to assess whether the overall sample participants represented a range of economic resource capabilities. The NZDep is a geographically derived indicator from the New Zealand census which categorises residential areas around income, home ownership, transport, living space, qualifications, communications and employment. The NZDep score is identified by 
address, and ranges from 1 (least deprived) to 10 (most deprived). For the most recent application of the index across New Zealand (NZ) in 2006 (Salmond, Crampton and Atkinson 2007), 15 per cent of research participants had NZDep address scores of 1-2 (NZ 25\%), 27 per cent scores of $3^{-4}(\mathrm{NZ} 23 \%), 17$ per cent scores of $5^{-6}(\mathrm{NZ} 20 \%), 21$ per cent scores of $7-8(\mathrm{NZ} 17 \%)$ and 20 per cent scores of $9-10(15 \%)$.

As the deprivation index is a geographical rather than individual measure, it cannot accurately assign individual deprivation scores. In formulating economic resource categories, the researchers examined material situations based on interview data including adequacy of income to meet the participants' needs, and drew on interviewer field notes regarding living conditions, including observations on dwelling quality, furnishings, warmth, repair and material possessions. Included in the categorisation were participant's own assessments of their level of financial wellbeing. Consequently, the broad categorisation by deprivation score was refined by comparing the deprivation score to the interviewers' written notes on the living conditions of the participants and the researchers' assessment of the individuals' material situations based the interview data. By drawing together these three types of information, we were able to assign participants to categories of low, mid and high economic resources (ER).

The semi-structured interviews were conducted between March 2010 and May 2011 . Eight of the interviews were with couples, but the remainder were conducted with individuals who lived in a variety of circumstances including living alone, with a spouse or partner, or with other relatives including adult children and grandchildren. ${ }^{1}$ All interviews were audio recorded and fully transcribed. The interviews explored various aspects of managing choices and decisions in everyday life, focusing on the role of economic resources and the practices which they enabled. Interview topics included purchasing and finances, access to transport, housing quality, characteristics of the community in which participants were located and influences on participation in social networks. To encourage people to reflect on capabilities arising from access to economic resources, participants were asked about their current and future aspirations, their degree of satisfaction with their overall standard of living, and to provide examples of things they wanted and needed to have and do, and to consider what they would change if they had more or fewer resources.

Using computer software Atlas.ti, participant data was coded and analysed for common themes which emerged through the range of participant talk. The guiding question for the analysis was 'How do older people talk about economic resources?', with a view to understanding the capabilities and freedoms which arise from economic resources. The initial thematic analysis identified six living standards domains which varied according to material 
resources and which could be understood as 'valued capabilities' (Sen 1999) which participants sought to achieve or do. These six domains which emerged from our research were the capabilities:

- to live in physical comfort;

- to be connected to others;

- to contribute to the lives of others;

- to experience enjoyment;

- to have the freedom to make choices;

- to be ontologically secure.

None of these domains were mutually exclusive. For example, capability of being secure could have a basis in the autonomy associated with choice, and in the experience of material comfort. Likewise experiencing enjoyment could be gained through a sense of feeling safe in particular places and having the ability to make choices in these contexts. The broad thematic analysis has been reported elsewhere (Breheny, Stephens and Mansvelt 2011) and was used to develop a measure of living standards for older people (Breheny et al. in press). The analysis reported here focuses on the domain of 'security' and while recognising that security is shaped through practice (Newton 2008), the findings show that security is experienced and expressed in participants' talk according to their level of economic living standards. Analysis of experiences of security was undertaken in relation to groups of participants with low, middle and high levels of economic resources. Quotations from transcripts are referred to by pseudonym, age, key social relationships, housing status and economic resource category (ER).

\section{Results and discussion}

Overwhelmingly, our analysis suggests that it is not economic resources per se which are the core of older people's concerns, but rather the ability of economic resources to enable people to make choices regarding their present and future physical and social environments and relationships. Across all ethnicities, ages and localities, the achievement of security was a valued capability. Security of income and possession of commodities and assets enabled participants across the economic resource spectrum to feel secure and to maintain some sense of surety in the face of change. Such ontological security also provided a sense of freedom, as expressed by Bob:

It's a wonderful sense of freedom not to have to think about money. (83, living alone in his own home with a spouse in residential care, high ER) 
It also provided the ability to respond to unexpected events, providing a kind of certainty and buffer for the challenges faced in everyday life, as Julie suggests:

I think financial safety is important to the old. I think when you get old you need not so much security as certainty, and you have a pattern of life and it's when there's a problem or being disturbed I think this is what is unsettling for the old. (9o, widow living with her son, low ER)

Many participants understood security as a means of coping with and retaining some control over life eventualities. Others such as Beryl and Brian in the excerpts which follow, spoke of the fear and insecurity that spoke of the fear and insecurity that arose from not having enough to cope with expenses, and the uncertainty of managing the unexpected:

Int: If for some reason, I hope it never happens, but if for some reason say the income that you're having now would be cut back? How, what are the things that you'd give up?

Beryl: Oh God. I don't know what I'd do. I'm frightened to know about it also because I don't think I can, you'd know, how can I live then?

Int: Right.

Beryl: I mean I'd have to live in one room, doing every blessed thing in one room. I'd much rather die. (86, widow living alone in her own home, mid ER)

And the thing is too you never know you might get a big car bill, that would have a huge impact on us, because if you spend it there is no way you can actually replace that money is there. (Brian, 76 , lives with his spouse in an independent dwelling in a retirement village, low ER)

Although security was valued across all participants, our analysis also revealed that the ways that security is understood and pursued varies according to the levels of economic and material resources. Surprisingly, those with most and least access to economic resources expressed the strongest sense of security, albeit in different ways, while those in the midrange of economic living standards expressed the highest sense of insecurity. The concerns of these participants with high, low and mid levels of economic resources are described in the sections which follow.

\section{High economic resources: the security of having enough to last one's lifetime}

For the wealthy, ontological security exhibited in a sense of wellbeing, safety, control over the future, order and continuity appeared to be linked to financial security. For those with considerable economic resources, security was articulated in terms of being sufficiently prepared for future eventualities as they aged, rather than as a matter of practical concern in everyday life. Having access to finances (income, savings, returns on investments), material resources (assets, home ownership or secure dwelling 


\section{Juliana Mansvelt et al.}

tenure, cars) and services (health, household, vehicle and other insurances, health, transportation, communication, home maintenance, leisure and retail services) allowed these older people to have a sense of control over their remaining years. A common theme which emerged from these participants was the lack of worry which arose from having sufficient finances at their disposal.

And we don't have any worries, really. (Walter, 91, lives with his spouse in their own home, high ER)

Int: For example another $\$ 5^{\circ}$ a week, would you notice that and would your spending change?

Tilly: I don't know. I'm happy with what I've got so I can't think of anything. I'd probably put it in the bank. (75, lives with her spouse on a rural property they own, high ER)

For such participants, more money would make no difference to their standard of living or experience of security. Financial security provided these participants with surety, expressed not only in an ability to control and allocate resources over the remainder of the lifecourse, but also to cope with and manage all but the most unavoidable and unforeseeable eventualities (such as terminal illness, significant disability, loss of all investments, failure or loss of key social relationships).

We feel that we've got enough to last us until we die. (Tony, 72 , lives with his spouse (still employed part-time) in their own home, high ER)

Ursula: Oh she [Financial Advisor] always telling me I could do a bit more.

Int: $\quad$ OK. So you could?

Ursula: Yes, I suppose I could. But you don't know how long you're going to live and you don't know what your needs are going to be. (77, separated, living alone in own home, high ER)

However, as Ursula in the previous quote indicates, a sense of security derived from a knowledge one had sufficient economic resources to last lifetime, was constituted in the context of the unpredictability of the future:

We don't know what time we will kick the bucket. (Sadar, 74, lives with his spouse in their own home, high ER)

Those with greatest access to economic resources, in common with those across the ER spectrum, recognised that health was one area in which the freedoms provided by economic resources (such as private health insurance, or an ability to pay outright for private social services and care) could not fully mitigate risks. Whilst acknowledging the limitations of material resources to overcome the unpredictability of health in later life, 
for those with access to extensive economic resources the fact that almost all possible financial eventualities were covered gave participants with higher levels of economic resources a sense of autonomy and control.

Int: Just say for example your fridge broke down tomorrow, would that be a problem to get a service person or indeed if it broke down ever and you needed to buy a new fridge tomorrow?

Graeme: We would do that... No problem we've got that buffer there all the time, [for] anything, I mean we're somewhat reluctant I suppose to be extravagant because we were brought up that way. (81, lives with spouse in own home, high ER)

Thus, for those with high levels of economic resources, ontological security was derived from a certainty of coping, a sense in which capability to manage, repair, replace and 'restore' in the face of all but the most unexpected events was assured.

\section{Low economic resources: the security of coping}

Besides employment security, the hazard of poverty in old age is one of the major issues in the evaluation of economic security (Berloffa and Modena 2012 ). In contrast to the wealthy, whose ample finances helped contribute to a sense of ontological security, participants with fewer economic resources often had experienced considerable insecurity in financial resources and income through their lifetimes. While it might be expected that these participants would express ontological insecurity, this was not the case. Despite their limited material capacities to choose and to access goods and services, those with few economic resources found security in the knowledge that they would continue to cope with the unexpected. For participants with low levels of economic resources, financial struggles were a part of the trials of everyday life. Coping with the everyday, managing on a budget and continuing to exist as one has always done appeared, however, to give many of these participants a sense of continuity and autonomy, as expressed by this participant:

If I've lived this long ... Without having heaters put in and all that sort of thing, well I'll live a bit longer. (Conny, 9o, widow living alone in own home, low ER)

While many acknowledged how nice it would be to 'have more to spend', and recognised the additional opportunities and choices this would provide them with materially and socially, the ways in which experiences were narrated demonstrated pride in their ability to manage within very constrained circumstances. 'Getting on', and 'making do', practices that had developed over the lifecourse, would continue to serve them well as they adjusted to new circumstances. 
Int: $\quad$ And any activities that would upset you if you had to go without?

Barbara: No, You just learn to adjust, you adjust to them. (74, divorced, living alone in own home, low ER)

Unrealistic expectations were seen as fanciful rather than helpful to coping, and Toa, like many other participants, expressed the adequacy of current consumption levels for managing:

It would be nice to have a beautiful car that cost about $\$ 30$,ooo but that is not important to me. I am alright with a bicycle. (Toa, 74, low ER)

Participants told stories in which financial insecurity was part of the continuity of their lives, something they had coped with and would continue to actively manage. Sarah, when asked about her spending, states:

Oh no I've got to be very careful how I spend. I've always been one to make sure that I've got plenty of cooking things in the house... (77, widow living alone in a rented house, low ER)

Throughout her interview Sarah recounted stores of coping with little, with her current ability to manage on a low income a consequence of a lifetime of economising and careful saving:

You were home with the children, and he, you know I mean my husband never got big wages. And I'll never forget, I used to save a little bit of money because I used to have to grate all my soap, make it and then grate it, you know to wash and everything ... And then I'd save a little bit of money, you know so I could buy a packet of soap powder.

The word 'security' hardly featured in participants' talk - the future was anticipated as 'business as usual' for many of these participants who had lived through and already successfully coped with difficult financial, material and social circumstances. The expectation of uncertainty was not viewed with a sense of trepidation or fear, but with a kind of certainty. For example, Craig when asked about managing with less, notes:

Oh yeah, I just have to tighten the belt a bit, but that's alright. (Craig, 77, widower living alone in own home, low ER)

The knowledge that struggle and overcoming were part of daily existence provided many with a sense of comfort, resilience and a sense of ontological security. Having coped before, for participants like Brian, in the quote which follows there was security in the knowledge that they would survive and withstand future trials whether these involved declining health, changes in social relationships or material conditions:

I don't think we've ever had a lot of money, we've never been ultra-rich or even pretty by that. So we've always been careful and I think people of our age group and in our social sort of whatever, always tended to have worked hard for what 
they had and didn't have a hell of a lot left over at the end of the week. (Brian, 76 , lives with his spouse in an independent dwelling in a retirement village, low ER)

For those with fewer economic resources, ontological security was not described in terms of the presence of external resources that can be drawn upon to buffer unexpected changes in physical health and material circumstances in later life, but the presence of personal resources that allow the incorporation of expected changes in health and standards of living over the remainder of their lives. Because these resources are internal, they represent a security which external resources cannot match for these participants. Research indicates older people draw on their overcoming of previous hardships as a means of coping with the present (Wellman et al. 1997). As Padgett (2007) suggests with regard to people who have suffered from mental illness, many older people who have experienced crisis and poverty may actually expect insecurity and uncertainty as a normal part of life. For Padgett's participants, a combination of external resources (e.g. a dwelling of their own) and internal resources (such as self-determination and hope) helped them establish constancy in their environment and cope with a still uncertain future. Similarly in this research, previous experiences of overcoming difficulty appeared to influence future expectations of coping with the acknowledged unpredictability of life.

A number of participants with lower levels of economic resources had achieved higher incomes and greater financial stability under New Zealand Superannuation than they had over their lifecourse. In his interview for example, Rua described how he and his wife's everyday life was still a financial struggle, but this had been made easier though receipt of superannuation from the age of $6_{5}$.

When we actually first came back, because I wasn't $6_{5}$, I wasn't qualified for the super at the time. It was hard then. Tried to make ends meet and trying to come within our bounds or the rules of WINZ [Work and Income New Zealand] but now, being on the pension and all that... (Rua, late sixties, lives with his spouse in a rental home, low ER)

Consequently, for many participants with lower levels of economic resources, greater security and stability of income combined with a set of internal resources understood through narratives of coping and of 'cutting one's cloth' to fit constrained circumstances, enabled those with limited economic resources to experience ontological security in later life.

\section{Mid economic resources: coping with insecurity through re-adjustment}

Participants in the mid-range of economic living standard exhibited the most ontological insecurity around their ability to cope with both expected and unexpected changes in future circumstances. The unpredictability 
of life combined with a potential inability to provide materially for the future was a cause for much greater anxiety and insecurity than was exhibited by those participants at either end of the economic resource spectrum.

Int: So it's [your life] sort of, very different from what you had visualised it would be?

Lila: It's certainly not what my husband had expected. When he went. At least he thought I'd be comfortable. Yeah. Anyway... (84, widow living alone in own home, mid ER)

In response to questions regarding how they would respond to a reduction in economic resources, participants in the mid-range of economic resources described the need for careful planning to adapt. Older people in these circumstances described how a reduction in financial resources would require them to think, to plan and to budget. For those with mid-range economic resources in situations of financial constraint, managing unpredictability was often about retaining control over consumption.

Int: So, what sort of things would you change if you had less to spend?

Tui: I'd probably have to look at what I really needed and what I could do without. And I guess I would have to change the way I think about clothes, or I'd have to change, well I've certainly changed already the kind of food that I buy and the meals that I prepare. And I've gone for more economical, healthy but economical choices, yeah. Probably I'd just look, overall I mean for instance shutting down medical insurance. I'm going to think about that. I don't want to get rid of insurances on property or life but the fact that I'm even thinking about it is an interesting challenge. $(67$, lives with her spouse in their own home, mid ER)

In the face of a standard of living which was often more austere (by choice and necessity) than that held during 'working life', making the right life choices, spending wisely and managing finances were seen as critical. Sen also acknowledged the impact of other influences which can affect the ability of individuals to transform economic resources into capabilities (Morris 2009). Unforeseen events such as sickness could provoke uncertainty, for example, when participants had to give up private health insurance because of the cost, or when they had to find the money for unexpected costs. Here Lila has had to pay for private surgery by taking a loan against the value of her housing asset, in order to receive financial peace of mind in the face of a cancer diagnosis:

Lila: Well I've had to have quite a bit done, get cancerous bits done on me. That's [inaudible]. So I've had to pay for it, I've had to borrow. 
Int: So that means you've had to take money against the house, take a mortgage against the house?

Lila: Yes. (84, widow living in own home, mid ER)

For some participants rising household costs and high-profile financial company collapses involving their retirement savings had contributed further to insecurity. Heather, who had lost most of her investments, explained how different life was now that she was living largely on New Zealand Superannuation.

I know, it was, I'd sort of got to a stage just before my husband died, where we'd got to a stage where we were living very comfortable thank you on our investments and national super which we'd only just started to get because it's the frill on top. Now I'm living on National Super and the bits I get from investments are the frills on top, you know, yeah. (Heather, widow living in own home, 77, mid ER)

Consequently the need for security as a capability may be blocked or frustrated by the circumstances people now find themselves in (Underlid 2007). In their interview talk, many mid ER participants spent time and effort in shaping their identities as 'coping' individuals endeavouring to resolve fears and tensions concerning their wellbeing, through framing their identity as responsible and self-managing citizens. Here Theresa discusses her anxiety about not having saved sufficiently for retirement. She plans to sell her house to release some capital but notes that the money would not be spent extravagantly:

But now younger people are told to save for their retirement. You don't think of that really as an important factor. But it is important. When I sell my house and invest the money, the balance, then I would have that little extra which would make life a lot easier. But I wouldn't want to [splash] out in any big way. But it would mean that you could, I don't really know, go to the pictures more, well not more often, I haven't been to the pictures for over a year. A friend just rung me this morning, he was saying 'yes, when's the special days?' It's $\$ 8$. (Theresa, 66 , single, living alone in own home, mid ER)

Most of those in the mid-range of economic resources had not had lengthy experiences of coping through such uncertainty, and unlike those at the top of the living standards scale they did not have the considerable economic resources available to provide a 'security blanket' for such events. For many, struggling to maintain previous material standards of living not only suggested a lack of preparedness for later life, but called into question future provision for their remaining years. The unpredictability of life was consequently difficult to integrate into such understandings and engendered considerable ontological insecurity and anxiety. 
The sense of unpredictability of life was highlighted in a study of displaced Hurricane Katrina survivors in New Orleans. This study found that the mental health impacts of the loss of material and financial resources, trust and the security of community membership were significant factors in loss of ontological security (Hawkins and Maurer 2010). In a similar but more everyday way perhaps, these factors are also at stake among those whose economic resources were in the mid-range. Having stability in material circumstance, having normal and regular routines and meaningful trust networks with others are important as markers of ontological security (Padgett 2007). However, the risk and uncertainties shaped through transition to retirement, the onset of ill health, change in family and financial circumstances, and a lack of sources of annuitised income for middle-income New Zealanders may provide additional uncertainties for older people in this cohort whose expectation for their later years has often been shaped by a life of relative comfort and security of income, autonomy and self-determination. Under these circumstances, maintaining the everyday and taken-for-granted 'rhythms of life' may be challenging (Padgett 2007: 1933) and the need to adjust to new practices which challenge one's sense of autonomy and independence may not be easy (Valkila et al. 2010).

\section{Conclusion: pursuing security and the capabilities derived from economic resources}

While Sen's capability approach implies that greater access to economic and material resources enable a greater range of freedoms and opportunities, this analysis indicates that there is not a straightforward relationship between economic resources and ontological security as it is perceived and pursued by participants. For the very wealthy participants in our study, experiences of coping in life had been greatly assisted by economic resources which had in the past, and would in the future, enable them to change and to adjust to all but the most unmanageable life circumstances. The capacity provided by economic resources for future security was acknowledged, but security was not a significant daily concern for many participants with considerable economic resources.

The life trajectories of those participants with least access to economic resources meant they often lacked the capacity to change their material circumstances and financial security was often a pressing and immediate concern. Nevertheless, although participants recognised that they lacked economic resources to overcome the unpredictability of everyday life, their previous experiences of coping through adversity meant that they continued 
to manage in an uncertain world. In addition for some, a higher and/or more reliable source of income through receipt of New Zealand Superannuation had actually provided greater security in retirement. Participants with lowest levels of economic resources consequently exhibited greater levels of ontological security than might have been expected.

However, those with mid-range economic resources had neither a historically developed capacity to cope with uncertainty, nor the capacity provided by economic resources to provide continuity and a sense of autonomy and control over their future. Many of these participants had experienced the security of a good household income gained from employment in their pre-retirement years, had saved conscientiously and contributed taxation, and had expectations for 'cradle to grave provision' from the State (Thomson 1996). With higher expectations of security, and in the face of concerns about the sufficiency of their economic resources to last their lifetime and the unpredictability of health and material circumstances, such participants were most anxious about their ability to cope and manage through difficulties.

The findings of the group of people with mid-range economic resources suggests that older New Zealanders with previously adequate material living conditions may lack confidence in the reliability of the economic system and the State to support predictable social and material outcomes as they age. Linz and Semykina's (2010) study of the perceptions of insecurity in Russia found that these were higher when economic conditions were deteriorating. Similarly, interview extracts indicate that many older people with mid-range economic resources were worried over whether their accumulated assets and economic resources would be adequate for their needs over their lifespan. Such anxieties may be compounded by expectations of a longer period spent in retirement and social imperatives to remain healthy and independent (Breheny and Stephens 2010) and to pursue a leisured lifestyle (Pond, Stephens and Alpass 2009, 2010).

In addition to this, the security of older New Zealanders with varying economic resources must be placed in its historical and social context. In New Zealand, the current cohort of older people have benefited from comparatively generous state provision of welfare benefits, subsidised health care, housing subsidies and supports, and free education over their working lives. Their expectations of the ability to manage, to make do and to age positively have reflected both their individual resourcefulness and the security of state support. Consequently, it is important to recognise that the attribution of ontological security to both internal resources and dispositions that have developed over the lifecourse, and to external and structural 
factors, occurs in and is influenced by specific temporal, political, economic and spatial contexts. Thus different welfare systems are likely to promote altered patterns of security across a gradient of economic resources. As mentioned previously, in New Zealand, with a relatively universal pension system, for some individuals who had been under-employed or unemployed prior to retirement the Superannuation pension provides more rather than less security. This might not be the case in contexts where State pensions are paid out at lower relative income levels and where access to and uptake of private pensions is low. Consequently, variations in State and private provision, means testing and/or taxing of pensions, and annuitised versus lump sum payments of pensions are all factors which may promote or undermine security for individuals with differing levels of economic resources. However, the universality of the way in which security was pursued across our range of participants suggests that, regardless of the context in which security is manifest, ontological security is a significant rhetorical arena for shaping identity and for moral ascriptions of both self and others as one ages. Further exploration is consequently needed to understand the ways in which security and identity are connected across a range of social and spatial contexts. Understanding how economic resources enable and restrict choices and opportunities for action and autonomy aligns with the aim of 'new materialist' work in social gerontology, which asks questions not just about what material resources are significant in everyday life, but about the work that they enable and perform in specific contexts (Chapman 2006).

The choices participants have available to them and their capacities to influence their current and future circumstances do differ across levels of economic resources, but not in a predictable gradient. Drawing on extracts from interviews with older people, we have demonstrated that issues of security are most problematic for those whose life opportunities and economic resources fall midway on a continuum of economic resources. While we might have expected participants in this group to express higher levels of security than those with less access to economic resources, this was not the case.

We argue that the cultural shaping of life trajectories and experiences and future aspirations of coping impact on the extent to which the capability of security is pursued and experienced. Our analysis suggests that what older people are seeking is not so much the purchasing power of economic resources, but the management of later life unpredictability. Ontological security does not remove risk, but it does enable it to become part of one's world of normalcy (Ring 2005). Not knowing what the future holds is an inevitable part of the embodied experience of later life, but ability to respond to the future in ways developed in the past is a means of ensuring ontological security. 
The effects of privilege and disadvantage infiltrate the everyday lives of people in subtle and pervasive ways (Mansvelt 2012), as this examination of the impact of economic position on the experience of security demonstrates. Examination of inequalities often focuses attention on the everyday life of the disadvantaged. There has been recent recognition of the limitations of focusing on the poor for understanding the reproduction of disadvantage (Stephens 2010) and a need to also focus on the everyday practices of the privileged to fully understand the experience of inequalities. The present study highlights the advantages of studying both the wealthy and the poor in order to understand the ways in which the capabilities that people value are shaped and constituted differently according to the context of varying life trajectories, experiences and expectations.

How differing economic living standards for those living in retirement are understood and to be acted upon is a matter of current contention (Berthoud, Blekesaune and Hancock 2006; Grundy and Holt 2001). We suggest that a more nuanced understanding of the intersection of economic resources and expressed dimensions of wellbeing such as ontological security can inform the practices of public-, private- and voluntary-sector groups which aim to enable individuals to deal with risks that are less likely to be mitigated by welfare states in the future (Ring 2005). Understanding more about the capabilities that are supported or undermined by structures and practices which alter both material entitlements and trust relations for particular groups of older people is critical. For example, while the unpredictability of one's health was an area of concern across all participants, for those in the mid-range of economic resources who had relinquished private health insurance because of the cost of premiums, the loss of what they saw as their opportunity to have 'timely' health care was a source of particular insecurity.

Thus if ontological security is an important part of wellbeing (WillsHerrera et al. 2011), then the implications of current social and economic policies such as retirement income, tax increases, health policies, housing and accommodation subsidies, must be considered, not just for those who are most materially deprived, but also for those whose ontological security and coping may be significantly challenged as they strive to age successfully. Social and economic policy to support successful ageing by a growing population of older people will need to recognise not only the financial implications of provision and resource allocation, but also the psychological, emotional and material effects of the experience of security and predictability in the face of changing circumstances faced by people as they age. Consequently, the research presented in this paper highlights the need to consider the complex ways in which economic resources are connected 
to other social and material aspects of everyday life to produce particular capabilities and outcomes. It is hoped that greater recognition of the varied and multiple factors which contribute to the capability to achieve and pursue ontological security will inform policies and practices which enable all individuals positioned differently with regard to social, structural and spatial relationships to age positively.

\section{Acknowledgements}

This research was supported by a grant from the Foundation for Research, Science \& Technology (now Ministry of Business, Innovation \& Employment) (ref. MAUXogo2). This project has been subject to ethical review and an application has been approved by the appropriate University Human Ethics Committee (ref. HEC/og/78). There are no conflicts of interests.

\section{NOTE}

1 None of the participants were in residential care, although some lived independently within retirement villages and with adult children and grandchildren.

\section{References}

Beck, U. 1992. Risk Society: Towards a New Modernity. Sage, London.

Berloffa, G. and Modena, F. 2012. Economic well-being in Italy: the role of income insecurity and intergenerational inequality. Journal of Economic Behavior $\mathcal{E}$ Organization, 81, 3, 751-65.

Berthoud, R., Blekesaune, M. and Hancock, R. 2006. Are 'poor' pensioners 'deprived'? Research Report No. 364, Department for Work and Pensions, London.

Breheny, M. and Stephens, C. 2010. Ageing in a material world. New Zealand Journal of Psychology, 39, 4, 1-8.

Breheny, M., Stephens, C., Alpass, F., Stevenson, B., Carter, K. and Yeung, P. Development and validation of a measure of living standards for older people. Social Indicators Research, in press. doi: 10.1007/s1 1 205-01 2-0188-4.

Breheny, M, Stephens, C. and Mansvelt, J. 2011. Developing a measure of living standards for older people using Sen's capability framework. In Proceedings of the 2nd International Workshop on the Socio-Economics of Ageing, 4th November 201 I. ISEG, Technical University of Lisbon, Lisbon, 1-22.

Carter, K. and Imlach Gunasekara, F. 2012. Dynamics of Income and Deprivation in New Zealand, 2002-2009. A Descriptive Analysis of the Survey of Family, Income and Employment (SoFIE). Public Health Monograph Series No. 24, Department of Public Health, University of Otago, Wellington.

Cattell, V., Dines, N., Gesler, W. and Curtis, S. 2008. Mingling, observing, and lingering: everyday public spaces and their implications for well-being and social relations. Health and Place, 14, 3, 544-61. 
Chandola, T., Ferrie, J., Sacker, A. and Marmot, M. 2007. Social inequalities in self reported health in early old age: follow up of prospective cohort study. British Medical Journal, 334, 7601, 990.

Chapman, S. A. 2006. A 'new materialist' lens on aging well: special things in later life. Journal of Aging Studies, 2o, 3, 207-16.

Commission for Financial Literacy and Retirement Income $2012 a$. 'Income Support', Policy Statement. Available online at http://www.cflri.org.nz/retirement-income/ policy-positions [Accessed 20 December 2012].

Commission for Financial Literacy and Retirement Income 2012b. 'Longevity Risk Pooling', Policy Statement. Available online at http://www.cflri.org.nz/retirementincome/policy-positions [Accessed 20 December 2012].

Commission for Financial Literacy and Retirement Income 2012c. Sorted. Your Independent Money Guide. Available online at https://www.sorted.org.nz/a-z-guides/ nz-super\#s3 [Accessed 31 October 2012].

Dixon, S. and Hyslop, D. 2008. The Employment and Retirement Transitions of New Zealanders Aged in their 6os. LEED Research Report, Statistics New Zealand, Wellington.

Dupuis, A. and Thorns, D. C. 1996. Meanings of home for older home owners. Housing Studies, 11 , 4, 48 $5^{-} 5^{\mathrm{o}}$.

Giddens, A. 1990. The Consequences of Modernity. Stanford University Press, Stanford, California.

Giddens, A. 1991. Modernity and Self-identity: Self and Society in the Late Modern Age. Polity Press, Cambridge.

Gilbertson, J., Stevens, M., Stiell, B. and Thorogood, N. 20o6. Home is where the hearth is: grant recipients' views of England's Home Energy Efficiency Scheme (Warm Front). Social Science and Medicine, 63, 4, 946-56.

Grundy, E. and Holt, G. 2001. The socioeconomic status of older adults: how should we measure it in studies of health inequalities? Journal of Epidemiology and Community Health, 55, 895-904.

Hawkins, R. L. and Maurer, K. 2011 . 'You fix my community, you have fixed my life': the disruption and rebuilding of ontological security in New Orleans. Disasters, $\mathbf{3 5}$, $1,143-59$.

Hiscock, R., Kearns, A., Macintyre, S. and Ellaway, A. 2001. Ontological security and psycho-social benefits from the home: qualitative evidence on issues of tenure. Housing Theory and Society, 18, 1, 50-66.

Jatrana, S. and Blakely, T. 2008. Ethnic inequalities in mortality among the elderly in New Zealand. Australian and New Zealand Journal of Public Health, 32, 5, 437-43.

King, P. and Waldegrave, C. 2009. Theoretical background. In Koopman-Boyden, P. and Waldegrave, C. (eds), Enhancing Wellbeing in an Ageing Society: 65-84 Year Old New Zealanders in 2007. EWAS Monograph One, Population Studies Centre, University of Waikato, Hamilton; and Family Centre Social Policy Research Unit, Lower Hutt, Wellington.

Laing, R. D. 1965. The Divided Self: An Existential Study in Sanity and Madness. Pelican Press, London.

Linz, S. J. and Semykina, A. 2010. Perceptions of economic insecurity: evidence from Russia. Economic Systems, 34, 4, 357-85.

Mansvelt, J. 2012. Consumption, ageing and identity: New Zealander's narratives of gifting, ridding and passing on. New Zealand Geographer, 68, 3, 187-200.

McHugh, K. E. 2007. Un-poetically 'man' dwells. ACME, 6, 2, $25^{8-77 .}$

Ministry of Social Development 201 2. Benefit Rates at I April 2o I 2. Available online at http://www.workandincome.govt.nz/individuals/forms-and-brochures/benefitrates-april-201 2.html [Accessed 8 January 2013]. 


\section{Juliana Mansvelt et al.}

Morris, A. 2009. Living on the margins: comparing older private renters and older public housing tenants in Sydney, Australia. Housing Studies, 24, 5, $693-707$.

Newton, J. 2008. Emotional attachment to home and security for permanent residents in caravan parks in Melbourne. Journal of Sociology, 44, 3, 219-32.

Noble, G. 2004. Accumulating being. International Journal of Cultural Studies, 7, 2, $233^{-} 5^{6 .}$

Padgett, D. K. 2007. There's no place like (a) home: ontological security among persons with serious mental illness in the United States. Social Science and Medicine, 64, 9, $1925^{-3} 6$.

Pond, R., Stephens, C. and Alpass, F. 2009. How health affects retirement decisions: three pathways taken by middle-older aged New Zealanders. Ageing Ev Society, 3o, 3, $527-45$.

Pond, R., Stephens, C. and Alpass, F. 2010. Virtuously watching one's health: older adults' regulation of self in the pursuit of health. Journal of Health Psychology, 15, 5 , $734-43$.

Ring, P.J. 2005. Security in pension provision: a critical analysis of UK government policy. Journal of Social Policy, 34, 3, 343-63.

Robeyns, I. 2005. The capability approach: a theoretical survey. Journal of Human Development and Capabilities, 6, 1, 93-117.

Salmond, C., Crampton, P. and Atkinson, J. 2007. NZDep2oo6 Index of Deprivation. Department of Public Health, Wellington.

Schulz, J. H. and Borowski, A. 20o6. Economic security in retirement: reshaping the public-private pension mix. In R.H. Binstock, L. K. George, S.J. Cutler, J. Hendricks and J.H. Schulz (eds), Handbook of Aging and the Social Sciences. Sixth edition, Academic Press, Burlington, Vermont, 360-79.

Sen, A. with Muellbauer, J., Kanbur, R., Hart, K. and Williams, B. 1987. The Standard of Living. Cambridge University Press, Cambridge.

Sen, A. 1999. Development as Freedom. Random House, New York.

Sen, A. 2ooo. Social exclusion: concept, application, and scrutiny. Social Development Papers No. 1, Office of Environment and Social Development, Asian Development Bank, Manila.

Stephens, C. 2010. Privilege and status in an unequal society: shifting the focus of health promotion research to include the maintenance of advantage. Journal of Health Psychology, 15, 7, 993-1000.

Stephens, C., Alpass, F., Towers, A., Noone, J. and Stevenson, B. 2011 . The effects of socioeconomic inequalities of working life on health: Implications for an ageing population. Kotuitui: New Zealand Journal of Social Sciences Online, 6 (1-2), 73-85. doi:10.1080/1177083X.2011.614264.

Thomson, D. 1996. Selfish Generations? How Welfare States Grow Old. The White Horse Press, Cambridge.

Townsend, P. and Davidson, N. 1982. Inequalities in Health: The Black Report. Penguin, Harmondsworth, UK.

Underlid, K. 2007. Poverty and experiences of insecurity. A qualitative interview study of 25 long-standing recipients of social security. International Journal of Social Welfare, 16, $1,65^{-74}$.

Valkila, N., Litja, H., Aalto, L. and Saari, A. 2010. Consumer panel study on elderly people's wishes concerning services. Archives of Gerontology and Geriatrics, $\mathbf{5} \mathbf{1}$, e66-71.

Wellman, N. S., Weddle, D. O., Kranz, S. and Brain, C. T. 1997. Elder insecurities: poverty, hunger, and malnutrition. Journal of the American Dietetic Association, 97, 10, supplement, $\mathrm{S}_{120-2 .}$ 
Wills-Herrera, E., Orozco, L. E., Forero-Pineda, C., Pardo, O. and Andonova, V. 2011. The relationship between perceptions of insecurity, social capital and subjective well-being: empirical evidences from areas of rural conflict in Colombia. Journal of Socio-Economics, 4o, 1, 88-96.

Accepted 7 May 2013; first published online 3 July $20 I_{3}$

Address for correspondence:

Dr Juliana Mansvelt

Geography Programme

School of People, Environment and Planning,

Massey University, Palmerston North 4442,

New Zealand.

E-mail: J.R.Mansvelt@massey.ac.nz 